\title{
Tecnologia e sociedade: entre os paradoxos e os sentidos possíveis
}

Fabio B. Josgrilberg

Mestre em Estudos da Mídia (Concordia University), doutorando em Ciências da Comunicação (ECA-USP) e Gerente de Projetos do Núcleo de Tecnologias Aplicadas à Educação da Universidade Metodista de São Paulo.

E-mail: fabiojosgrilberg@metodista.br.

\section{Mas se há um sentido do real, e ninguém duvidará que ele tenha seu direito à existência, deve haver também qualquer coisa que podemos chamar de sentido do possivel ${ }^{1}$ \\ Robert Musil, O Homem Sem Qualidades}

1. MUSIL, R. L'homme sans qualités $(O$ homem sem qualidades). Tome 1. Paris: Seuil, 1995. p. 19.

2. Cf. POCHMANN, Márcio. O desemprego na globalização. São Paulo: Boitempo, 2001.
O Brasil é palco, há alguns anos, de processos eleitorais que podem ser considerados, com seus defeitos e sucessos, indicadores dos possíveis usos das tecnologias de informação e comunicação para o fortalecimento de certos aspectos do regime democrático. Não está em questão, neste texto, o modelo de democracia brasileiro que, na verdade, pouco tem de democrático em termos de distribuição de renda e na garantia de alguns direitos básicos. Numa perspectiva mais ampla, o próprio conceito de democracia é tema de debate - não se fala da mesma democracia no Brasil, na Suécia ou nos EUA. No entanto, é inegável que a tecnologia contribuiu para um processo extremamente complexo, em um país de dimensões continentais, e, de alguma forma, para a organização da sociedade. Se tomarmos o termo democracia em sentido lato e considerá-lo como objetivo, a experiência brasileira é digna de registro.

Também é merecedor de nota o fato de, no Brasil, a taxa de desemprego aberto aumentar por anos consecutivos, de a criação de postos de trabalhos ocorrer com mais freqüência em setores considerados menos habilitados e de que há uma concentração crescente de postos qualificados nos países de economia capitalista avançada². É verdade que tal cenário não é fruto apenas da incorporação das tecnologias de informação e comunicação, mas principalmente de um sistema capitalista que as precede; sistema que, no entanto, depende dessas tecnologias para organizar as transações de mercado financeiro, a cadeia de produção distribuída globalmente, a automação de diversos setores, entre 
outras atividades. Trata-se, conforme definição dada por Castells, do chamado paradigma informacional responsável pela sustentação do sistema capitalista e da aceleração dos processos globalizantes ${ }^{3}$.

A tecnologia, como promotora de possibilidades democráticas e fomentando processos de exclusão social, é fruto de uma dinâmica cheia de paradoxos. Porém, é nessa contradição que Sérgio Amadeu da Silveira vê uma oportunidade: "A ambigüidade do processo em curso permite lutar por seu direcionamento"4. Não são poucos os autores que caminham nesse sentido. Para Gilberto Dupas, por exemplo, "a tecnologia pode e deve se submeter a uma ética a fim de

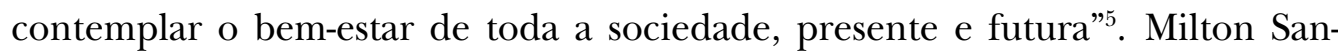
tos, por sua vez, sugere que "na sua forma material, unicamente corpórea, as técnicas talvez sejam irreversíveis, porque aderem ao território e ao cotidiano. De um ponto de vista existencial, elas podem obter um outro uso e uma outra significação" ${ }^{6}$. Este texto também pretende pensar o sentido da tecnologia e, dessa forma, está em diálogo com as posições acima. A noção de sentido deve ser entendida aqui como os caminhos possíveis, ou seja, as possibilidades de novos usos.

Antes de iniciar a discussão sobre o sentido da tecnologia, um pequeno, mas necessário, esclarecimento. Há propostas que tratam de tecnologia em termos de meios materiais e, em outros casos, como técnica social (processos, saber sistematizado) de organização do espaço e da sociedade. Em outras perspectivas, as técnicas também podem ser entendidas como inerentes ao ser humano e as tecnologias, como os meios.

Este texto partirá das observações feitas por Octavio Ianni sobre o fato de que "toda tecnologia, à medida que é inserida na sociedade ou no jogo das forças sociais, logo se transforma em técnica social"’. Entender-se-á, portanto, que, mesmo em sua forma material, os meios estão indissociavelmente ligados a relações sociais específicas que visam dominar a natureza, organizar o espaço e a sociedade.

Retomando a discussão sobre a orientação dada ao uso da tecnologia, seria correto, então, afirmar que a tecnologia é neutra, ou seja, pode ser submetida a vários usos? A questão é antiga, mas vale lembrar algumas posições. Para Hebert Marcuse, o "a priori tecnológico é um a priori político" e, dessa forma, está diretamente ligado a uma determinada organização da sociedade. $\mathrm{O}$ autor destaca a frase de Marx: "O moinho manual te dá a sociedade com o senhor feudal; o moinho a vapor, com o capitalista industrial”. Marcuse, no entanto, reconhece que dentro das perspectivas marxistas essa determinação é revista e que o modo social de produção, e não a técnica, é o fator histórico básico. Ainda assim, mantém a seguinte posição: "Quando a técnica torna-se a forma universal de produção material, ela circunscreve uma cultura inteira, ela projeta

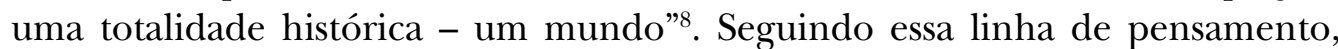
não seria demais imaginar que as tecnologias de informação e comunicação nos deram uma sociedade com Microsoft e IBM, consolidaram o poder das corporações transnacionais e suas cadeias produtivas, facilitaram a movimentação financeira ou até mesmo de plantas industriais inteiras. Isso para não falar
3. CASTELLS, Manuel. A sociedade em rede. São Paulo: Paz e Terra, 2000. v. 1, p. 78.

4. SILVEIRA, Sérgio Amadeu. Exclusão digital: a miséria na sociedade da informação. São Paulo: Perseu Abramo, 2001 p. 16.

5. DUPAS, Gilberto. Ética e poder na Sociedade da Informação. São Paulo: Unesp, 2000. p. 18.

6. SANTOS, Milton. Por uma outra globalização: do pensamento único à consciência universal. Rio de Janeiro: Record, 2001. p. 174.

7. IANNI, Octavio. Teorias da globalização. Rio de Janeiro: Civilização Brasileira, 1998. p. 86.

8. MARCUSE, Hebert. One-dimensional man: studies in the ideology of advanced industrial society (A ideologia da sociedade industrial: o homem unidimensional. Rio de Janeiro: Zahar, 1982). Boston: Beacon Press, 1964. p. 154. 
9. COHN, Gabriel. A forma da sociedade da informação. In: DOWBOR, L. et al. (Orgs.). Desafios da comunicação. Petrópolis: Vozes, 2001. p. 21.

10. CASTELLS, Manuel, op. cit., p. 41

11. Gráficos adaptados a partir dos modelos apresentados por SILVEIRA, Sérgio Amadeu, op. cit., p. 14. nos chamados megainvestidores ou megaespeculadores internacionais; não são eles, de certa forma, um produto das tecnologias desenvolvidas nas últimas três décadas? Algumas linhas do pensamento comunicacional, especialmente de Marshall McLuhan, sugerem um determinismo tecnológico ainda maior, de caráter um tanto psicologizante, ou seja, alterando os modos de percepção humana. A idéia foi imortalizada na célebre frase "o meio é a mensagem", cunhada pelo autor na década de 1960. Outras perspectivas, mais ligadas à lingüística e à semiótica, tratam até de uma gramática da tecnologia que circunscreve seu uso.

Não entraremos aqui nas especificidades de cada teoria. Deve-se estar atento, no entanto, ao fato de nas atuais relações sociais o paradigma informacional marcar, ao que tudo indica, até mesmo a forma de compreensão da realidade. Existe, seguindo a crítica de Cohn, uma sobredeterminação da lógica informacional, ou seja, da forma binária dos uns e zeros da informática ${ }^{9}$. Só é possível estar dentro ou fora da rede - informática e capitalista. O próprio termo inclusão digital revela tal sistematização do pensamento. Aparentemente influenciado por essa lógica, Castells, por exemplo, sugere que, quando a Rede desliga o Ser (individual ou na forma de grupos sociais), pode haver um afastamento recíproco ${ }^{10}$. No entanto, se o universal empírico propiciado pelas técnicas, como será discutido adiante, é um fato ou está num horizonte próximo, seria esse afastamento realmente uma possibilidade? O Ser excluído, explorado, não seria constitutivo do poder da Rede? Também não seria uma ilusão imaginar que a tensão é eliminável?

A própria metáfora da rede, que aparentemente organiza o imaginário da globalização em suas diversas facetas (rede capitalista, rede tecnológica, rede de conhecimento, gerenciamento em rede, rede de solidariedade etc.), poderia ser posta em questão. O modelo pressuposto é o de rede distribuída, em oposição às redes centralizadas ou descentralizadas. De acordo com esse modelo, diferentes pontos estão interconectados sem uma hierarquia clara - trata-se de uma forma de poder difuso - e a eliminação de um dos pontos não interrompe o fluxo de informação no resto da rede. Tudo isso baseado na existência de um protocolo comum que garanta o fluxo de informação.

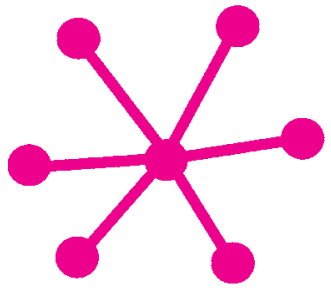

Centralizada

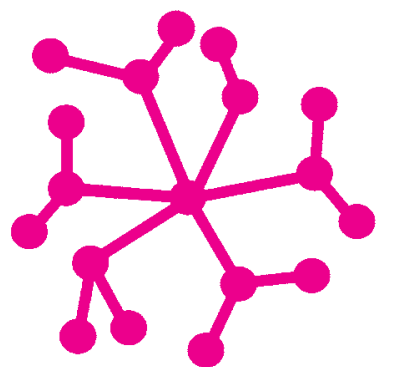

Descentralizada

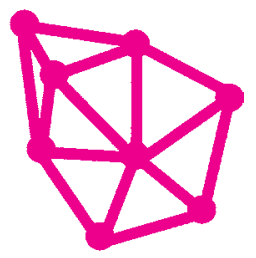

Distribuída
Modelos de redes ${ }^{11}$

A aplicação ingênua dessa metáfora para a organização da sociedade ignora os jogos de poder e as hierarquizações entre os diversos atores, além de vislumbrar a possibilidade de alguns pontos serem eliminados sem grandes 
prejuízos para o funcionamento da rede como um todo. Ainda que seja essa a metáfora que organize o imaginário da globalização, talvez ela não represente a mais adequada para os objetivos de uma sociedade que luta para reduzir desigualdades, mesmo que a igualdade total seja utópica em termos de relações humanas - em qualquer grupo social haverá autoridades baseadas numa tradição, em jogos de poder ou em acordos simbólicos. A participação na rede distribuída ocorre em diferentes velocidades, com diferentes capacidades de veiculação de signos, entre outras diferenças ${ }^{12}$.

A metáfora da rede, com supostos atores em igualdades de condições, de alguma forma, repete a receita de economia liberal de mercado ortodoxa. Um modelo e uma linguagem são impostos sem grandes atenções para o resultado social. Quem não obedece ao protocolo estabelecido é punido. De certa forma, não é isso que acontece quando financiamentos são negados pelo Fundo Monetário Internacional (FMI) a países que procuram estratégias econômicas alternativas, mesmo que dentro dos moldes capitalistas, ou a governos que não acompanham o ritmo dos processos de privatização, liberalização comercial e do sistema financeiro, na velocidade pretendida pelo Fundo? Pouco importa o custo social de implantação das políticas propostas pelo FMI, porque o essencial é garantir e aumentar o poder da rede capitalista que, teoricamente, alavancaria o desenvolvimento das regiões mais pobres ${ }^{13}$. É claro que tais orientações não são reflexos apenas de um determinado uso da tecnologia, mas esta contribui, e muito, para a sistematização das idéias que organizam a sociedade a partir da metáfora da rede.

Dada a influência da tecnologia na organização e percepções que se tem da realidade, ainda que relacionada a outros fatores culturais, poder-se-ia concluir, então, que a tecnologia não é neutra? Sim, ela não é neutra, porém a resposta exige uma melhor elaboração a fim de evitarmos um determinismo imobilizador das ações humanas. O retorno à teoria crítica, especialmente, serve como primeira e necessária etapa de reflexão. É preciso estar atento ao deslumbramento, por vezes enganoso, que as novidades tecnológicas exercem. As tecnologias dominaram o espaço, mas não houve obrigatoriamente o desenvolvimento de melhores relações humanas. Na verdade, em alguns casos, a deterioração é gritante. Nesse sentido, vemos a conveniência de retomar alguns aspectos levantados por tais teóricos, ainda que considerados por muitos pesquisadores atuais como ultrapassados - condenação que muitas vezes lembra atividades sacrificiais que visam garantir a estabilidade de determinados grupos sociais.

Uma tecnologia incorporada por uma sociedade altera as relações sociais, a percepção do espaço, do tempo, ou seja, modifica a relação do ser humano com a natureza e entre os próprios seres humanos. Não importa se para melhor ou pior, há uma mudança na relação com o mundo e na compreensão que se tem dele. Argumentar que o computador, o telefone, a faca ou qualquer outro instrumento sozinho não altera a organização do espaço pode ser uma posição enganosa. A tecnologia só tem significado em seu uso dentro de relações sociais dadas. Logo, a tecnologia necessariamente está para alguém. Vista dessa forma, ela não é neutra. No entanto, não se trata de uma posição
12. Cf. SANTOS, Milton, op. cit., p. 83

13. Cf. STIGLITZ, J. E. A globalização e seus malefícios: a promessa não cumprida de benefícios globais. Tradução de Bazán Tecnologia e Lingüística. São Paulo: Futura, 2002. 
determinista. Sua adoção sujeita-se a tensões que também condicionam, alteram e questionam seu uso.

Criticar o determinismo tecnológico, no entanto, não significa de forma alguma negar as fortes pressões que a adoção de uma tecnologia exerce na sociedade, especialmente sob as condições capitalistas vigentes. Por isso, insistimos, ainda que autores como Marcuse não tenham elaborado a utilização das tecnologias e das relações fomentadas pela racionalidade técnica propositivamente, esse tipo de crítica ainda é muito revelador de determinadas dinâmicas sociais. Tal visão crítica também parece ser um contraponto interessante para as teorias que retomam a atividade criativa dos sujeitos no ato de recepção que, se os devidos cuidados não forem tomados, podem descambar para um populismo teórico, extremamente acrítico, onde tudo é consumido festivamente.

\section{O LUGAR E O ESPAÇO DO OBJETO TÉCNICO}

Um outro registro teórico talvez possa ajudar a esclarecer a posição pretendida neste texto. Michel de Certeau, em L'invention du quotidien 1. Arts de faire ${ }^{14}$, trabalho de boa penetração nos estudos da recepção, busca entender a dinâmica social em termos de lugar, espaço controlado por relações de poder, e espaço, o lugar praticado. $\mathrm{O}$ autor define como estratégias as operações que organizam o lugar e como táticas as que orientam o espaço. Os movimentos táticos não possuem lugar próprio; partem do lugar organizado pelas estratégias. Em outras palavras, haverá sempre uma organização, condicionada por relações de poder, que precede a ação dos sujeitos. Nem mesmo uma revolução alterará essa condição. Todo grupo social carece de autoridades, simbólicas ou individuais, que permitem sua organização ${ }^{15}$. Portanto, não se trata de uma relação do espaço contra o lugar, mas da existência do espaço no lugar. Há uma coincidência geográfica, mas não na dinâmica e forma de operar, como, por exemplo, na relação com o tempo e no uso do espaço. Uma maneira simplificada de pensar essa dinâmica é através da reflexão sobre a relação da leitura (movimento) com o texto escrito (espaço com o tempo controlado) ${ }^{16}$.

Toda tecnologia nasce dentro de uma organização social específica, ou seja,

14. Cf. CERTEAU, Michel de. L'invention du quotidien 1. Arts de faire (Invenção do cotidiano 1. Artes do fazer). Paris: Gallimard, 1990.

15. Id. La culture au pluriel (A cultura no plural). Paris: Seuil, 1993. p. 17.

16. Cf. JOSGRILBERG, Fabio B. Michel de Certeau e mídia: táticas subvertendo lugares ou lugares organizando táticas? Comunicação \& Sociedade, São Bernardo do Campo: PósCom-Umesp, n. 37, p. 31-34, 1. sem. 2002. num lugar, conforme o vocabulário de Certeau. No caso da sociedade atual, os objetivos dos cientistas, as relações capitalistas, os discursos hegemônicos e as diversas estratégias de controle do espaço social orientarão o papel da novidade. No entanto, a sociedade é complexa e contraditória, caso contrário seria um sistema perfeitamente equilibrado. Diferentes sujeitos irão garantir diversos usos da tecnologia a partir do lugar organizado pelas relações de poder. Essas variações são determinadas por situações contingentes, por uma memória e operações táticas, ou seja, pela utilização do espaço com base em outras percepções do mundo vivido. Mas como isso seria possível? Tais usos não são determinados pelas estruturas? O sistema não reabsorve esses diferentes usos?

Discutir a questão dos usos é questionar a possibilidade de agência; é pensar a chance de direcionamento do processo em curso. Ora, imaginar que são 
possíveis diferentes usos é vislumbrar uma dissociação entre linguagem e poder, entre o uso da linguagem e sua estrutura, como o fizeram Ludwig Wittgenstein (o significado enquanto uso), Émile Benveniste (teoria da enunciação) e a Retórica (figuras de linguagem). Em uma outra perspectiva teórica, a fenomenologia (Ex.: Edmund Husserl, Maurice Merleau-Ponty, Aflred Schutz) é levar em conta as vivências do sujeito e compreender sua relação com o mundo; compreensão que pode ser reveladora das contradições do sistema predominante. Sob um registro dialético, é interpretar o processo histórico e as tensões que forçam o movimento social (Ex.: Karl Marx, Hegel). Todas essas linhas de pensamento apontam para possibilidades de agência. Não se trata de relativismo teórico citá-las nesta breve reflexão; relativismo seria deixá-las cada uma em seu nicho, numa espécie de "politicamente correto teórico" sem confrontá-las, sem colocá-las em diálogo. Apesar das profundas diferenças epistemológicas que marcam essas perspectivas, é possível reconhecer nessas orientações teóricas uma circulação de significados possíveis sobre a questão da agência.

Se for correto afirmar que o sistema ou estrutura absorve tais alterações, os novos usos, também será dizer que as alterações não cessam de ocorrer a partir das novas configurações de poder. Existe uma circularidade na relação espaço/lugar em que não é possível identificar o limite entre um e outro, seja em termos geográficos ou temporais. Trata-se de uma relação dialética na qual as estratégias, fundadas num poder alcançado, organizam na maioria das vezes, mas não sempre, o espaço próprio (lugar controlado). Os movimentos táticos, por sua vez, utilizam o lugar para atuar e interferir no equilíbrio, ainda que de forma inconsciente, por não haver um referente fixo que dite a verdade da organização social - no caso discutido aqui, o uso das tecnologias. Essa relação dialética não remete, em essência, a uma estrutura previamente organizada, mas, através de movimentos por vezes imperceptíveis aos olhos de administradores e pesquisadores, altera a organização do espaço, configura novos lugares. $\mathrm{O}$ direcionamento da tecnologia está sujeito a essa tensão essencial. O importante é não ignorar a forte sistematização das relações sociais, mantendo-se, porém, atento às brechas e fissuras que permitem alteração do sentido.

\section{CIVILIZAÇÃO E DESCIVILIZAÇÃO}

É verdade que alterações drásticas raramente ocorrem. Porém, se é possível reconhecer a possibilidade de alteração do sentido da tecnologia, ainda que de maneira lenta e por vezes imperceptível, também se faz necessário evitar a supervalorização desses movimentos. Tais exageros ocorrem principalmente entre analistas e administradores afoitos em assinar sua "carta ao príncipe". Se o "Great Refusal' de Marcuse pode parecer pouco provável, deslumbramento com a Aldeia Global pode ser extremamente inconseqüente. É sempre bom lembrar as observações feitas por Laymert Garcia dos Santos, quando ele critica "o fascínio exercido pela tecnologia enquanto encarnação da racionalidade, de razão operante, em todo o mundo contemporâneo (seja os que defendem 
17. SANTOS, Laymert Garcia dos. Desregulagens: educação, planejamento e tecnologia como ferramenta social. São Paulo: Brasiliense, 1981. p. 23.

18. Cf. ELIADE, Mircea. Ferreiros e alquimistas. Rio de Janeiro: Zahar Editores, 1979.

19. Ibid., p. 138.

20. SCHAFF, A. A sociedade informática. São Paulo: Editora Unesp/Brasiliense, 1995. p. 22; 30.

21. MARCUSE, Hebert, op. cit., p. 17

22. DE MASI, Domenico. $\mathrm{O}$ ócio criativo. Trad. Lea Manzi. Rio de Janeiro: Sextante, 2000. p. 264.

23. DUPAS, Gilberto, op. cit., p. 102. o capitalismo, o socialismo ou uma terceira via), e a impossibilidade de pensar o 'fato técnico' senão como um fato positivo precisamente porque ele é portador de razão, aquele que traz em si, mas também que a conduz e que a representa" ${ }^{17}$.

A posição pouco crítica em relação às atuais tecnologias pode mascarar as profundas contradições presentes no sistema capitalista. Tal posicionamento parece ser fruto, em parte, da crença na técnica para a solução de problemas que, na verdade, são de caráter político. O mito soteriológico em relação à técnica ecoa a eterna ambição humana de substituir o trabalho do tempo, o trabalho da natureza, em busca de redenção. Como sugere Mircea Eliade ${ }^{18}$, "o mito soteriológico [dos alquimistas] e, em última análise, da redenção da Natureza sobrevive, camuflado, no programa patético das sociedades industriais" ${ }^{19}$.

É interessante notar como o fascínio pela técnica atinge os mais diferentes campos - políticos de esquerda, centro ou direita, intelectuais, religiosos etc. -, mesmo nos dias de hoje. O mito soteriológico também sobrevive na era das telecomunicações, informática e genética, anunciando a possibilidade de novas relações entre povos, programas educacionais, distribuição de informação, curas, produção de alimentos e tantos outros sonhos. As diferentes tecnologias, de fato, aceleram a criação, a produção e a circulação de itens necessários à sobrevivência. No entanto, num ambiente capitalista, elas podem aumentar também a circulação de produtos supérfluos ou que suprem necessidades criadas a partir do próprio desenvolvimento técnico da sociedade, bem como aumentar o risco de eventuais crises de demanda. Por exemplo, uma crise provocada pelo aumento da produção e cortes de empregos graças, em parte, à incorporação de tecnologia sem as bases sociais necessárias para acompanhar o processo, como políticas para a geração de novos empregos ou seguros compatíveis com as necessidades dos novos desempregados.

O sentido da tecnologia para promover melhores relações humanas, portanto, entra em choque com a necessidade do sistema capitalista de manter relações específicas de divisão do trabalho e de mais-valia. Schaff chega a sugerir que a segunda revolução técnico-industrial, a das tecnologias eletrônicas e informáticas, "aspira à eliminação total" do trabalho, e essa evolução levaria à necessidade de rever o conceito de propriedade atual ${ }^{20}$. Porém, esse paradoxo, pacificação da existência e necessidade de lucro, é, segundo Marcuse, o elemento irracional da racionalidade técnica: "Quanto mais a tecnologia parece capaz de criar as condições para pacificação [da existência humana], mais as mentes e corpos do homem estão organizados contra essa alternativa" ${ }^{21}$. Diante das relações humanas atuais, ao que parece, a tendência ou possibilidade de eliminação do trabalho, idéia que circula entre outros autores como, por exemplo, Domenico De Masi ${ }^{22}$, soa pouco estimulante.

Um outro fator paradoxal, ilustrativo dos problemas enfrentados com o avanço das tecnologias, é a questão ecológica. O padrão de consumo norte-americano ou europeu, identificado como paradigma para os países em desenvolvimento, é incompativel com as reservas naturais do planeta ${ }^{23}$. Dessa forma, ainda que 
ocorra uma revisão dos usos e que, de algum modo, se busque amenizar ou eliminar o paradoxo entre a pacificação da existência e o sistema capitalista, há necessidade de uma revisão geral dos padrões culturais ocidentais de vida, ou seja, daquilo que é consumido. Trata-se de um problema de relações humanas, e não de máquinas.

Todos esses paradoxos parecem apontar para as ambigüidades destacadas por Norbert Elias em sua análise da relação entre a incorporação de tecnologia e o processo civilizatório. Para o autor, parece haver uma tensão entre integração versus desintegração e processo civilizatório versus processo descivilizatório (decivilization). Elias nota que, no caso do automóvel, as vantagens oferecidas tornam algumas desvantagens aceitáveis - a morte em acidentes (descivilização). Há, no entanto, uma força para auto-regulação no uso desses veículos que varia de cultura para cultura e pouco tem a ver com o nível de incorporação da tecnologia - o processo civilizatório é uma questão de humanos para humanos ${ }^{24}$. As tecnologias de informação e comunicação, responsáveis pela convergência das diversas técnicas, também possuem esse caráter ambíguo de civilização/ descivilização. Difícil, porém necessário, é estabelecer a auto-regulação nos diversos campos em que tais tecnologias atuam - comunicação, genética, produção etc. - especialmente em função dos fortíssimos interesses corporativos em jogo. Quais seriam as desvantagens que estão se tornando aceitáveis em função da incorporação do paradigma informacional? Até que ponto elas são aceitáveis? A questão é extremamente complexa em função da ubiqüidade das tecnologias de informação. Não se trata apenas de analisar o computador ou o telefone celular, mas de refletir sobre o paradigma informacional nas relações sociais, nas ciências médicas e exatas.

Em contrapartida, a onipresença das tecnologias da informação e comunicação aponta para um aspecto que pode ser altamente positivo. Pierre Lévy identificou nessas tecnologias o advento da cibercultura que coloca virtualmente a humanidade diante de si mesma. Essa nova era marca um novo universal por contato, sem ser totalizante de sentidos, que, de certa forma, é herdeiro dos projetos dos filósofos do século XVIII ${ }^{25}$. Se as idéias de Lévy sobre alguns caminhos da cibercultura soam otimistas demais para a realidade latino-americana - um tanto conservadoras também, exatamente por não levar em conta essa realidade e apenas apontar para um futuro ideal -, imaginar uma humanidade diante de si parece ser uma pista interessante e promissora. As contradições geradas por esse universal técnico podem forçar uma dinâmica social com vistas à redução da desigualdade, se não por vontade dos grupos hegemônicos, por reivindicação e pressão dos submetidos a condições menos favoráveis. Essa proximidade mediada pode ser reveladora das diferenças, assim como o é a realidade urbana. Conforme sugestão de Milton Santos, nos centros urbanos a proximidade das pessoas garante maior possibilidade de resistência - o geógrafo discute também a universalidade empírica criada pelas técnicas. Santos, contudo, adverte que "a consciência da diferença” pode levar a estratégias individualistas e não necessariamente a um "sistema alternativo de idéias" ${ }^{26}$. Logo, a simples proximidade,
24. Cf. ELIAS, Norbert. Technization and Civilization (Tecnização e Civilização). The Norbert Elias Reader, Oxford: Blackwell Publishers, p. 212-229 1998.

25. LÉVY, Pierre. Cibercultura. Trad. Carlos Irineu da Costa. São Paulo: Editora 34, 2000. p. 245-247

26. Cf. SANTOS, Milton, op. cit., p. 92; 116 
27. IANNI, Octavio. Enigmas da modernidademundo. Rio de Janeiro: Civilização Brasileira, 2000. p. 148-149.

28. OFFE, Claus. A atual transição da história e algumas opções básicas para as instituições da sociedade. In: BRESSER PEREIRA, L. C.; WILHEIM, Jorge; SOLA, Lourdes (Orgs.). Sociedade e Estado em transformação São Paulo/Brasília: Editora Unesp/ENAP, 1999. p. 127

29. CERTEAU, Michel de. La prise de parole (A tomada da palavra). Paris: Desclée de Brouwer, 1968. p. 21. mediada pela tecnologia, pode não ser suficiente para novas possibilidades de organização social. Mais que isso: a ubiqüidade das tecnologias também expressa "a visão do mundo prevalecente nos blocos de poder predominantes". É o chamado príncipe eletrônico, "o intelectual coletivo e orgânico das estruturas e blocos de poder", segundo a análise feita por Ianni ${ }^{27}$.

A relação dialética entre lugar (espaço controlado) e espaço (lugar praticado) pode ser novamente ilustrativa para se pensar as questões discutidas anteriormente. O universal empírico criado pela técnica se apresenta como o espaço controlado que serve de palco para ações diversas, até mesmo para o desenvolvimento de novas solidariedades, participações políticas, percepção da diferença ou de articulações que podem reinventar determinadas relações humanas. Essas possíveis reinvenções (utilização do lugar, espaço praticado), quando ocorrem, podem ser incorporadas ao lugar, passam a fazer parte das autoridades simbólicas que permitem a existência de um grupo social. Portanto, o lugar já não é mais o mesmo. Muitas vezes tais utilizações do espaço não alteram ou apenas contribuem para a manutenção de relações de poder extremamente injustas. Haverá sempre esse risco. No entanto, o eventual reforço de certas configurações espaciais não representa o fim da dinâmica lugar/espaço. Há aspectos perversos, mas a abertura de possibilidades sempre se renova.

A contribuição de pesquisadores na área de comunicação pode consistir, entre outros aspectos, na reflexão sobre o desenvolvimento e a criação de condições para essas novas sociabilidades. A simples distribuição dos meios técnicos não garante mudanças nas relações sociais. A pesquisa sobre a presença das tecnologias de informação e comunicação na sociedade deve buscar aquilo que Claus Offe tenta vislumbrar, ou seja, uma nova concepção de progresso como "capacidade de evitar continuamente a recaída no barbarismo e em formas catastróficas de descivilização" 28 . O desafio é identificar as possibilidades sem perder de vista a forte sistematização das relações sociais e, conseqüentemente, do uso da tecnologia numa sociedade capitalista como a atual. Reconhecer o ato criativo por parte de consumidores, usuários ou leitores, não implica negligenciar a crítica às estruturas de poder. De fato, é preciso ir além. Diante do reconhecimento de processos de tradução, mediações culturais ou de novos usos, é preciso pensar propositivamente formas de aumentar essa circulação de sentidos, bem como de carregá-los de força suficiente para alterar os processos de desumanização em curso. Como dizia Certeau, em sua análise dos protestos estudantis de 1968 em Paris, há uma diferença entre tomar a palavra, alterar o sentido e assumir o trabalho que é necessário ser feito ${ }^{29}$. Desenvolvendo a análise, a alteração de sentido abre uma possibilidade que, eventualmente, se instala de maneira imperceptível. Em muitas vezes, no entanto, há a necessidade de ações que fortaleçam e garantam a continuidade de um movimento iniciado. 
Resumo: O texto apresenta uma reflexão sobre as possíveis formas de incorporação das tecnologias de informação e comunicação nas sociedades atuais. Busca destacar a tensão entre organizações sistêmicas e o ato criativo no uso dessas tecnologias. Através da análise das relações de poder, especialmente a partir de referências propostas por Michel de Certeau, pretende pensar a utilização do potencial tecnológico para a reinvenção das atuais relações humanas dentro de uma economia capitalista.

Palavras-chave: tecnologia, teoria crítica, teoria da comunicação, recepção, Michel de Certeau.
Abstract: The text presents a reflection on possible forms of incorporating information and communication technologies in present societies. It highlights the tension between systemic organizations and the creative act in the use of these technologies. Through the analysis of power relations, especially since the references proposed by Michel de Certeau, it is intended to think the use of the technologic potential for the reinvention of current human relationships inside the capitalist economy.

Keywords: technology, critical theory, communication Theory, reception, Michel de Certeau. 